\title{
A brief analysis of the bridge between sports and
}

\section{The environment -- Ecological Sports}

\author{
Zhao Peng ${ }^{1, a}$ Ya Wei Song ${ }^{2, b}$ \\ ${ }^{1}$ Nanjing Sport Institute,Nanjing City Jiangsu Province \\ ${ }^{2}$ Nanjing Sport Institute,Nanjing City Jiangsu Province \\ a593471464@qq.com b516805946@qq.com
}

\begin{abstract}
Keywords: Sports. Environment. Ecological sports
\end{abstract}
Abstract: This paper mainly uses literature survey to summarize the concept and connotation of ecological sports from different scholars and the related concepts of ecological sports. First, it describes the application of ecological sports in Olympic, school sports, Chinese traditional sports and outdoor activities. Second, it focuses on the combination of ecological sports and different kinds of fields, and forms "New Sports".

\section{Preface}

The sports industry is developing vigorously in China since it is promoted by the implementation of national policy, the demand of sports, the trend of social development. The issue of "sports and environment" has aroused people's attention. Some Chinese scholars draw the attention of the new ideas, which are about the Green Olympics, the sustainable development of sports, the lifelong sports and so on. Wang Jinglian and Zhao Chongzhen put forward the coordinated development of sports and environment firstly, which from the Green Sports - the combination of the East and West sportsmanship in 1997.The article digs out the overall dynamic harmony including man and nature, man and man, and themselves. ${ }^{[1]}$ This also belongs to the category of ecological sports. As the imbalance of the development of sports, the domestic scholars put forward the concept of ecological sports and study sports from the view of ecology. It is a bridge between sports and environment.

\section{the research of Ecological sports theory}

In our country, some scholars have put forward a narrow concept of ecological sports. First , Ecological sports are defined as sports activities, such as rock climbing, skating, mountaineering, and so on, with the help of various natural environments. ${ }^{[2]}$ Second, Ecological sports refers to the lack of antagonism and competitiveness in the pursuit of freedom and frankness of human beings. There are various forms of ecological sports activities. It is Called "spontaneous sports". ${ }^{[3]}$ The explanation is narrow. It only explains the natural environment and its own environment. Nowadays, sports have developed rapidly in the natural environment and social environment. Therefore, ecological sports refer to sports activities that are constructed by the coordination, mutual care, symbiosis and common development of sports, culture and ecological environment. Ecological 
sports refer to the sports in the natural environment and the social ecological environment, which shows the health and personality of human beings. Ecological sports show humanistic care and humanitarianism, and ecological sports advocating a healthy, civilized and harmonious way of life, so that achieve sustainable development. ${ }^{[4]}$

Ecological sports are link with some other concepts. There are a few points. The concept of ecological sports is a new concept of treating nature, sports and human beings. Externally, the concept of ecological sports focuses on the coordination and sustainable development between sports phenomenon and natural ecology. The basic purpose of ecological sports is to build sports that live in nature. Internal, ecological sports pay attention to the relationship between sports and people. It advocates a harmonious value orientation between sports and people. Ecological sports pursue the ultimate concern between sports and people. ${ }^{[5]}$ Ecologicalization sport is a specific practice that is carried out in the sports field during the process of advocating ecological civilization, emphasizing the concept and value orientation of sports. ${ }^{[6]}$ The development of sports ecology is a development model of scientific coordination and ethical regulation. There are two main, first, ecological sports can achieve high efficiency and effectiveness of development, and promoting the coordinated development of sports human and humane; second, ecological sports can not only get out of a green, harmonious and sustainable development of Sports Road, but also realize people's all-round development and form the ultimate goal of social development. ${ }^{[7]}$ The understanding of sports function is divided into three stages. Initially, people only recognize the physical activity and the education function. With the further development of society, sports have political, cultural and economic functions. Now, the understanding of sports function returned to physical activity and education, to some extent reflects ecological sports. ${ }^{[8]}$ The ecological sports circle is a sports circle or venue that combines sports competition, fitness exercise, entertainment and leisure, sightseeing, ecological protection, sports business and sports science and technology. The ecological sports circle is based on the coordination among people, sports and environment. It takes sports and ecological environment as the basic carrier, views physical activity as a form of participation, and thinks the way of healthy and civilized life as its appeal. ${ }^{[9]}$

\section{Study on the application of ecological sports}

\section{Green Olympics}

The idea of green Olympic Games is one of the three pillars of the Olympic spirit. The green ecological Olympic project in Beijing is a sustainable development project of knowledge economy, which is in harmony with the natural environment. It is also a project for the coordinated development of Olympic Sports objectives and the economic circle of the host city. The green Olympic concept has realized the social structure function, the health function and the social ecological system harmoniously and uniformly. ${ }^{[10]}$ Green Olympic is essentially an ecological green. The Green Olympics include natural ecology, economic ecology and human ecology, the harmonious structure and function, and the healthy system green of the operation mechanism. ${ }^{[11]}$

\section{School Physical Education}

In the field of school sports, the main problems are involved in lacking the understanding of the school sports teaching environment, blocking teaching environment, lacking space, emphasizing the indexation of body mass, paying attention to deviate, lighting sports, lacking teachers, and include the essence of sports culture, the reform of slow process of physical education, sports and cultural degeneration, family factors etc. The teaching model of "ecological sports" is applied to 
school physical education. The teaching mode of ecological sport breaks the shackles of traditional physical education, harmoniously integrates human, sports and natural environment, promotes students' physical and mental health and strengthens students' sports consciousness. $\left.{ }^{[12}\right]$ Lei Hui, Deng Luoping, Zhang Tiexiong and others pointed out that the establishment of ecological index system for school physical education is to promote the construction and development of school sports Ecologicalization effectively. The ecological indicators mainly include 4 first grade index, 12 two grade index and 68 three grade index. It is of great practical significance to apply ecological sports to physical education. ${ }^{[13]}$ Extracurricular sports activities are an important part of school sports. The ecological factors that the restrict students participate in extracurricular physical exercise are mainly field equipment, campus environmental problems, campus geography, climate problems and interpersonal communication problems. The school should emphasize the idea of putting people first, provide an ecological sports campus environment, construct after-school sports ecological club, expand the ecological sports curriculum, and develop the direction of extracurricular physical training in the direction of health, civilization, harmony, green and humanity. ${ }^{[14]}$

\section{Sports tourism}

The development of ecological sports tourism should take into account the factors of climate, nature, human resources and local economic development. We should take advantage of ecological environment and seize the historical opportunities to make sports tourism a distinctive tourism. Developers should make good use of sports cultural resources to maximize the use of environmental advantages. Sports tourism should also realize the transformation from the government sports to the market sports, and explore a "light asset" sports industry development model. ${ }^{[15]}$ The region should make full use of the ecological environment to carry out sports projects and integrate with the natural environment, so as to make progress in sports, culture, economy and other parties. The development of regional ecological sports events, such as skiing, skating, mountaineering and so on, should follow the law of ecological civilization and make human, sports and environment develop harmoniously. ${ }^{[16]}$ Ecological sports tourism is a new way for the development of tourism. Chen Hao, Ren Yuyong, Wang Li, Li Hanxu, Qu, Sun Shuangming, pointed out that the establishment of ecological sports tourism, sports tourism resources evaluation system of ecological system and ecological heritage protection and development of sports tourism scenic spot competitiveness index system, the establishment of the system can ensure the sustainable development of ecological sports resources. ${ }^{[17]}$ Eco sports tourism is a popular tourism in the world. Considering the nature of tourism resources, the ecological sports tourism can be divided into two categories: natural ecological sports tourism and humanistic ecological sports tourism. The characteristics of ecological sports tourism include: fitness and entertainment, return to nature, the protection of tourism environment, the sustainability of development and utilization, the development of sports economy and the promotion of social progress. ${ }^{[18]}$

\section{Chinese Traditional Sports}

There are many traditional sports in China, such as stone locks, stilts, kite flying, etc. these traditional sports have a long history, but some sports are gradually lost. Modern sports originate in the west, and it is difficult to succeed in the attempt to transform the traditional sports activities with western sports. The eastern sports researchers should take another way to foster strengths and weaknesses, use scientific methods to further explore and improve the traditional health care culture, explore the unique resources that have existed in the East for the thousands of years, and build the system of original sports development with the help of the backwardness of the Eastern peoples. $\left.{ }^{[19}\right]$ Chen Yonghui pointed out that we should build the rural folk sports circle, create China 
fitness sports, leisure sports service system construction, ecological development of popular national sports, expand campus ethnic sports, strengthen ecological civilization construction of the national traditional sports culture, promote ecological civilization. ${ }^{[20]}$

\section{Outdoor activities}

Outdoor sports is a group of collective projects which is held on a natural site, including rock climbing, parkour, camping, and expedition. Here are two ecological sports. They are rock climbing and Parkour. Rock climbing is a typical outdoor sports, and it requires that climber establish a natural and harmonious ecological environment concept, explore the full range of natural value, comply with the law of development of nature, and strive to build a good situation of harmonious coexistence between man and nature, harmonious development, comprehensive and coordinated development of the relationship between man and nature. ${ }^{[21]}$ Parkour regards the surrounding environment as a big stadium, a form of return to nature. Taking the city as an example, the Parkour takes the urban environment as a sports condition for running, jumping, climbing, climbing and so on. ${ }^{[22]}$

\section{Summary}

Although it is not long to research Chinese ecological sports, it has achieved great results. In the field of theoretical research, scholars have put forward different views, which lays a theoretical foundation for the following study of ecological sports. Sport in China is in an unbalanced state, such as, the construction of Olympic stadiums, destruction of the ecological environment, the violation of the Green Olympics concept. The school sports teaching mode is not good that people do not pay attention to the sports environment and the combination of the three parts. The problem of sustainable development of sports tourism has not been a reasonable solution. According to the actual situation of sports in China, scholars have analyzed these problems with the aspect of ecological research, and put forward the idea of innovative significance.

\section{Acknowledgements}

This work was financially supported by the project of "12th Five-Year" of education science of Jiangsu province in 2015 - Study on the effects of ecological sports environment on the physical health of young people (T-c/2015/009)

\section{References}

[1] Wang Jing Lian, Zhao Chongzhen. Green Sports - the combination of sports spirit between East and West [J]. Journal of Chengdu Sport University, 1997 (01): 15-20.

[2] $\mathrm{Xu}$ Chuanbao. Sports ecology -- the theoretical basis of ecological sports [J]. Journal of Shenyang Sport University, 2001 (4):87-89.

[3] Chen Xueyan, Zhao Ying, Wang Xiliu, et al. Science and technology sports and ecological sports -- a new model of future sports development [J]. East Sports Science and technology, 2002, 24 (2):58-60.

[4] Xu Chuanbao. Ecological sports: the core concept of Green Olympics [J]. Journal of Chengdu Sport University, 2002 (5): 25-28.

[5] Li Fengmei, Zhu Haitao. Exploration of the value of ecological sports [J]. Journal of Chengdu Sport University, 2011, 01): 54-7. 
[6] and Chen Shuqi. The route of the [J]. sports culture guide, explains the meaning of ecological sports development in 2017, 09): 1-5.

[7] Zhou Zhijun, Liang. Deep ecological sport view philosophy [J]. sports journal, 2009,16 (04): 16-19.

[8] Xiong Huan, Zhang Aihong. Body, society and sports - Sports [J]. sports science from the perspective of western scholars, 2011, 06): 81-6.

[9] Fu Qun, Xiao Shuhong, Chen Xiaoli, Peng Huiwen. The concept, connotation and denotation of the ecological sports park [J]. Journal of Nanjing Sport Institute (SOCIAL SCIENCE EDITION), 2015,29 (05): 44-51.

[10] Liu Xinmao, Cheng Zhongguo, Xu Gang, Liu Fengping. The Beijing Olympic Green Ecological Environment and humanistic environment [J]. Journal of Wuhan Sports Institute, 2005 (10): 35-37.

[11] Wang Rusong, Wang Feng year. Ecological research on Green Olympics in Beijing [J]. Journal of Tsinghua University (PHILOSOPHY SOCIAL SCIENCE EDITION), 2001 (02): 68-71+94.

[12] Huang Aifeng, Wang Jian. On the 10 major problems in the development of school sports [J]. Beijing sports newspaper, 2015,38 (02): 95-99+121.

[13] Lei Hui, Deng Luoping, Zhang Tiexiong. Construction of the ecological index system of school sports [J]. Journal of Wuhan Sports Institute, 2008 (09): 28-31+48.

[14] Yin Weizeng, Zhang Deli, Cha Jian Fang. Taking people as the basis, constructing the ecological development of extracurricular sports in Colleges and universities in China: a case study of Higher Agricultural Universities in China [J]. Journal of Beijing Sport University, 2012,35 (06): 93-97.

[15] Huang Yi, Wang Guoqing. Study on ecological model [J]. Journal of physical education development strategy of sports industry in Guizhou Province, 2016 (05): 138-142.

[16] Hao Jianping. The utilization and development of ecological sports events in the city circle of Poyang Lake, [J]. sports science and technology documents, 2016,24 (12): 6-7+16.

[17] Chen Hao, Ren Yu Yong, Wang Li, Li Hanxu, Qu Jin, Sun Shuangming. The sustainable development of eco sports tourism in Beijing Hangzhou canal [J]. Journal of Beijing Sport University, 2015,38 (04): 26-32.

[18] Liu Fengyun. The Countermeasures of ecological sports tourism and its sustainable development [J]. Journal of Shenyang Sport University, 2005 (01): 17-19.

[19] Hu Xiaoming. The original ecological culture body fieldwork [J]. sports journal, 2015,22 (03): $1-10$.

[20] Chen Yonghui. A study on the ecological civilization and construction of national traditional sports under the view of "beautiful China" [J]. Journal of Wuhan Sports Institute, 2013,47 (09): 41-45+49.

[21] Feng Daoguang. Rock climbing on [J]. Journal of physical education, 2015 (01): 51-54.

Guo Lisan. Study on the development of [22] [J]. sports culture daokan parkour, 2009 (12): 19-22. 